\title{
EFICIÊNCIA DAS MINICEPAS E MICROCEPAS NA PRODUÇÃO DE PROPÁGULOS DE CLONES DE Eucalyptus grandis ${ }^{1}$
}

\author{
Miranda Titon ${ }^{2}$, Aloisio Xavierr ${ }^{3}$, Geraldo Gonçalves dos Reis ${ }^{3}$ e Wagner Campos Otoni ${ }^{4}$
}

\begin{abstract}
RESUMO - No presente estudo objetivou-se avaliar a eficiência dos jardins clonais nas técnicas de microestaquia e miniestaquia de quatro clones de Eucalyptus grandis, quanto a sobrevivência, vigor e capacidade produtiva das microcepas e minicepas em coletas sucessivas de microestacas e miniestacas. As microcepas utilizadas foram oriundas de mudas rejuvenescidas por micropropagação, mediante subcultivos in vitro, e as minicepas, de miniestacas oriundas de plantas propagadas pelo método da estaquia convencional (macroestaquia). As minicepas e as microcepas apresentaram desempenho similar, tendo sido observado, para ambas, elevada taxa de sobrevivência, vigor e capacidade produtiva de material para propagação vegetativa.
\end{abstract}

Palavras-chave: Eucalyptus, miniestaquia, microestaquia e propagação vegetativa.

\section{EFFICIENCY OF MINISTUMPS AND MICROSTUMPS OF Eucalyptus grandis CLONES FOR MINICUTTING AND MICROCUTTING PRODUCTION}

\begin{abstract}
The objective of this work was to evaluate the efficiency of clonal gardens in the microcutting and minicutting techniques of four Eucalyptus grandis clones regarding the survival, vigor and productive capacity of the microstumps and ministumps in successive collections of microcuttings and minicuttings. The microstumps were obtained from rejuvenated tissue explants through subculture in vitro, and the ministumps by minicuttings derived from conventional rooted cuttings. The ministumps and microstumps of $\boldsymbol{E}$. grandis exhibited similar performance, i.e., high survival rate, vigor and productive capacity of vegetative propagation material.
\end{abstract}

Key words: $\quad$ Eucalyptus, minicutting, microcutting and vegetative propagation.

\section{INTRODUÇÃO}

Na propagação clonal do gênero Eucalyptus, técnicas de rejuvenescimento têm visado contornar problemas de enraizamento encontrados em certos clones selecionados (Hacket, 1987, Bonga, 1992). Melhorias altamente significativas têm sido obtidas através da microestaquia (Assis et al., 1992; Xavier \& Comério, 1996; Silva, 2001) e da miniestaquia (IPEF, 1996; Xavier \& Wendling, 1998; Higashi et al., 2000). Essas técnicas têm proporcionado consideráveis ganhos em produtividade, uniformidade e aumento no porcentual de enraizamento das estacas, quando se consegue rígido controle ambiental, fitopatológico e nutricional do jardim clonal.

Também, a microestaquia e a miniestaquia têm possibilitado a substituição dos jardins clonais de campo para viveiros. Dentre as principais vantagens dessa inovação destacam-se o menor envolvimento de mão-de-obra (Assis, 1996); redução em investimentos em casa de vegetação, em razão da maior rapidez de enraizamento; eliminação do jardim clonal de campo, disponibilizando a área para plantios comerciais (Xavier \& Comério, 1996); e controle mais efetivo de pragas, doenças,

1 Recebido para publicação em 29.1.2002.

Aceito para publicação em 9.9.2003.

2 Engenheira Florestal, M.S.; ${ }^{3}$ Prof. do Departamento de Engenharia Florestal - UFV; ${ }^{4}$ Prof. do Departamento de Biologia Vegetal da Universidade Federal de Viçosa - UFV, 36570-000 Viçosa-MG. 
fertilização e da irrigação, resultando em melhoria da qualidade das mudas (Higashi et al., 2000; Silva, 2001).

Dentre as desvantagens apresentadas estão a maior suscetibilidade dos jardins clonais às variações ambientais (Silva, 2001); a necessidade de mão-de-obra qualificada; o maior controle sobre as atividades de manejo, planejamento e elaboração de atividades de produção das mudas (Xavier \& Wendling, 1998); e o custo decorrente do rejuvenescimento dos clones para o processo de microestaquia (Assis, 1997).

Avanços recentes, relatados por Silva (2001), referem-se à migração do microjardim clonal convencional para o microjardim clonal em sistema hidropônico, definido como hidrojardim clonal, o que proporcionou a minimização de vários problemas de propagação relativos, principalmente, à sazonalidade e produção de microestacas.

Apesar desses avanços, são escassas as divulgações científicas quanto à eficiência das técnicas de microestaquia e de miniestaquia em termos comparativos de jardim clonal. Portanto, o presente trabalho teve por objetivo avaliar a eficiência da microestaquia e da miniestaquia na produção de propágulos, visando a propagação vegetativa de quatro clones de Eucalyptus grandis W. Hill ex Maiden, em que foram analisados a sobrevivência, o vigor e a capacidade produtiva das microcepas e minicepas em coletas sucessivas de microestacas e miniestacas.

\section{MATERIAL E MÉTODOS}

Foram utilizados quatro clones de Eucalyptus provenientes da Empresa Celulose Nipo-Brasileira S.A. (CENIBRA), localizada no município de Belo Oriente$\mathrm{MG}$, sendo dois clones de Eucalyptus grandis (CC1 e CC8) e dois de híbridos de Eucalyptus grandis obtidos na região de Rio Claro-SP (CC11 e CC12).

Para constituição do jardim microclonal foram utilizadas mudas oriundas de material micropropagado, através da proliferação de gemas axilares, conforme detalhado em Titon (2001), sendo esta etapa desenvolvida no Laboratório de Cultura de Tecidos II do Instituto de Biotecnologia Aplicada à Agropecuária (BIOAGRO) da Universidade Federal de Viçosa.

Após a micropropagação, as gemas alongadas in vitro foram transplantadas para casa de vegetação localizada no Viveiro de Pesquisas do Departamento de

R. Árvore, Viçosa-MG, v.27, n.5, p.619-625, 2003
Engenharia Florestal da Universidade Federal de Viçosa, em Viçosa-MG, para o enraizamento ex vitro. Após o enraizamento em casa de vegetação (permanência de 30 dias), as mudas foram transferidas para aclimatação em casa de sombra, com sombrite $50 \%$, por um período de dez dias, seguidas, posteriormente, de rustificação a pleno sol. Quando atingiram de 10 a $12 \mathrm{~cm}$ de altura, as mudas tiveram seus ápices decepados na altura de $8 \mathrm{~cm}$, para obtenção das microcepas, que forneceram as microestacas para formação do jardim microclonal, conforme descrito em Xavier \& Comério (1996).

Para composição do jardim miniclonal, foram utilizadas minicepas obtidas do enraizamento de miniestacas oriundas de brotações de plantas propagadas pelo método da estaquia convencional, conforme a técnica de miniestaquia descrita por Xavier \& Wendling (1998) e Wendling (1999). As miniestacas enraizadas, ao atingirem de 10 a $12 \mathrm{~cm}$ de tamanho, tiveram seus ápices podados na altura de $8 \mathrm{~cm}$, constituindo, assim, as minicepas.

Os jardins clonais foram instalados em condições cobertas no Viveiro Florestal da CENIBRA. Como recipientes para as microcepas e minicepas foram utilizados tubetes de plástico de $55 \mathrm{~cm}^{3}$, contendo substrato constituído de partes iguais de vermiculita de granulometria média e casca de arroz carbonizada. O sistema de manejo do jardim clonal foi o mesmo adotado pela empresa, o qual foi composto por bandejas de aço inoxidável, sobre as quais permaneceram as microcepas e minicepas, acondicionadas em tubetes dispostos em bandejas de plástico rígido.

A irrigação e a nutrição mineral foram efetuadas através de um sistema automatizado de fertirrigação por inundação, de maneira que somente o sistema radicular permanecia em contato com a solução nutritiva. Esta solução continha nitrato de cálcio $\left(555 \mathrm{~g} / \mathrm{m}^{3}\right)$, sulfato de amônio $\left(200 \mathrm{~g} / \mathrm{m}^{3}\right)$, ácido fosfórico $\left(70 \mathrm{~g} / \mathrm{m}^{3}\right)$, cloreto de potássio $\left(210 \mathrm{~g} / \mathrm{m}^{3}\right)$, sulfato de magnésio $\left(150 \mathrm{~g} / \mathrm{m}^{3}\right)$, ácido bórico $\left(3,33 \mathrm{~g} / \mathrm{m}^{3}\right)$, sulfato de zinco $\left(0,15 \mathrm{~g} / \mathrm{m}^{3}\right)$, sulfato de cobre $\left(0,40 \mathrm{~g} / \mathrm{m}^{3}\right)$, sulfato de manganês $\left(1,67 \mathrm{~g} / \mathrm{m}^{3}\right)$, sulfato ferroso $\left(5,22 \mathrm{~g} / \mathrm{m}^{3}\right)$, EDTA $\left(6,96 \mathrm{~g} / \mathrm{m}^{3}\right)$ e molibidato de sódio $\left(0,05 \mathrm{~g} / \mathrm{m}^{3}\right)$.

Semanalmente, as microcepas e minicepas foram irrigadas por um sistema de aspersão durante 30 minutos, visando remover o acúmulo de sais no substrato. Com relação ao uso de fungicidas nos jardins clonais, foi aplicada, semanalmente, uma mistura de Benlate (1 g/l) e Captan $(2,4 \mathrm{~g} / \mathrm{l})$. 
Os jardins clonais foram dispostos em delineamento inteiramente casualizado, segundo o esquema fatorial constituído de duas técnicas (microestaquia e miniestaquia) e quatro clones (CC1, CC8, CC11 e CC12), com seis repetições e 20 microcepas/minicepas por repetição. A capacidade produtiva das microcepas e das minicepas foi avaliada mediante coletas semanais de microestacas e de miniestacas de tamanho variando de 4 a $6 \mathrm{~cm}$, durante 60 dias (outubro a dezembro de 2000), totalizando oito coletas. Para avaliação da produção mensal, considerouse a soma de quatro coletas semanais, observando a sobrevivência das microcepas e minicepas a cada coleta.

Para avaliação do vigor das microcepas e minicepas, foi realizada uma poda drástica nas microcepas e minicepas e, posteriormente, feito o acompanhamento da velocidade de emissão das brotações através de medições efetuadas aos $3,6,9,15$ e 20 dias, adotandose três classes de tamanho $(1=0,5$ a $2,0 \mathrm{~cm} ; 2=2,1$ a $4,0 \mathrm{~cm}$; e $3>4,0 \mathrm{~cm}$ ). Ao término dos 20 dias, foi realizada a avaliação do peso de matéria seca das brotações. O delineamento experimental utilizado nesta avaliação foi o inteiramente casualizado, no esquema fatorial constituído de quatro clones e duas técnicas, em seis repetições e parcelas compostas de uma microcepa/minicepa.

Os dados observados foram submetidos à análise de variância e aos testes de médias (teste de Scott-Knott e Tukey).

\section{RESULTADOS E DISCUSSÃO}

De acordo com os resultados da análise de variância da produção de microestacas e miniestacas por microcepas e minicepas (Quadro 1), observa-se que houve efeito significativo quanto à interação clones, técnicas utilizadas e coletas realizadas. Esses resultados indicam a diversidade de resposta dos clones em relação à microestaquia e miniestaquia e às coletas sucessivas, o que concorda com resultados obtidos por Xavier \& Comério (1996) e Wendling (1999) e, portanto, reforça a importância do material genético na propagação vegetativa (Chalfun, 1989; Zobel, 1993).

Observou-se mortalidade praticamente nula das microcepas e minicepas no decorrer das oito coletas realizadas. A taxa de sobrevivência das microcepas e minicepas (superior a 98\%) indicou alto potencial de resposta dos clones à emissão de novas brotações, através do sistema de coleta, o que concorda com os resultados obtidos por Wendling et al. (2000) em miniestaquia. Os resultados obtidos evidenciam que a metodologia adotada no presente estudo, quanto à condução dos jardins clonais, é tecnicamente viável, possibilitando a produção de microestacas e miniestacas de clones de Eucalyptus grandis em sucessivas coletas.

A produção de microestacas e miniestacas dos clones individualmente, ao longo das oito coletas, bem como as médias dos quatro clones por coleta, está representada na Figura 1.

Em termos gerais, a produção de microestacas/ microcepa e de miniestacas/minicepa mostrou-se semelhante, exceto para o clone $\mathrm{CC} 1$, cujos resultados obtidos por meio da miniestaquia foram superiores aos da microestaquia. Considerando os quatro clones, a produção média mensal foi de 8,5 e 9,7 na microestaquia e na miniestaquia, respectivamente. Comparando esses resultados com os obtidos por Xavier \& Comério (1996) e Wendling et al. (2000), fica evidente a redução do intervalo entre uma coleta e outra e o aumento na produção por coleta. Provavelmente, essa diferença esteja associada aos clones (genótipo) e ao manejo adotado da fertirrigação, cuja nutrição equilibrada permitiu o desenvolvimento mais vigoroso das brotações.

Quadro 1 - Resultados da análise de variância da produção de microestacas e miniestacas por microcepas e minicepas por coleta (PC) e mensal (PM) dos quatro clones de Eucalyptus grandis, avaliados em oito coletas

Table 1 - Results of the analysis of variance of the microcutting and minicutting production per microstumps and ministumps per collection (PC), and monthly (PM) for the four Eucalyptus grandis clones, evaluated in eight collections

\begin{tabular}{|l|r|r|c|c|}
\hline \multirow{2}{*}{ FV } & \multicolumn{2}{|c|}{ GL } & \multicolumn{2}{c|}{ Quadrado Médio } \\
\cline { 2 - 5 } & PC & PM & PC & PM \\
\hline Clone (Clo) & 3 & 3 & $3,4933^{* *}$ & $13,9731^{* *}$ \\
Técnica (Tec) & 1 & 1 & $7,7345^{* *}$ & $30,9379^{* *}$ \\
Coleta (Col) & 7 & 1 & $10,9747^{* *}$ & $36,3712^{* *}$ \\
Clo * Tec & 3 & 3 & $2,7834^{* *}$ & $11,1334^{* *}$ \\
Clo * Col & 21 & 3 & $0,8356^{* *}$ & $1,4841^{*}$ \\
Tec * Col & 7 & 1 & $0,9797 * *$ & $7,6022^{* *}$ \\
Clo * Tec * Col & 21 & 3 & $0,4559^{* *}$ & $3,1971 * *$ \\
\hline Resíduo & 320 & 80 & 0,1605 & 0,4247 \\
\hline Média geral & & & 2,28 & 9,12 \\
\hline CV (\%) & & & 17,58 & 7,15 \\
\hline
\end{tabular}

$* \mathrm{e}^{* *}=$ significativos a 5 e $1 \%$ de probabilidade, respectivamente, pelo teste F.

R. Árvore, Viçosa-MG, v.27, n.5, p.619-625, 2003 


\section{Clone CC1}

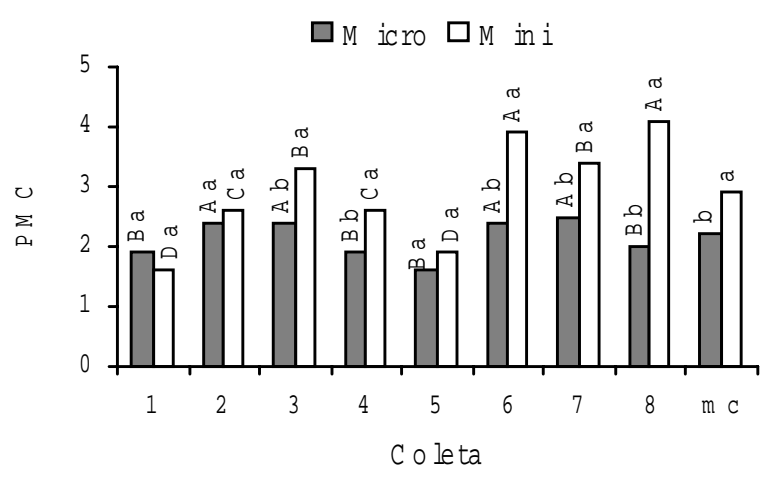

Clone CC11

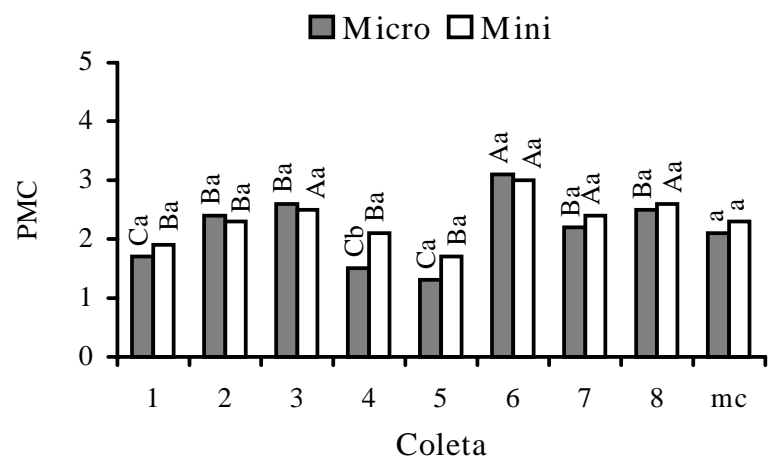

\section{Clone CC8}

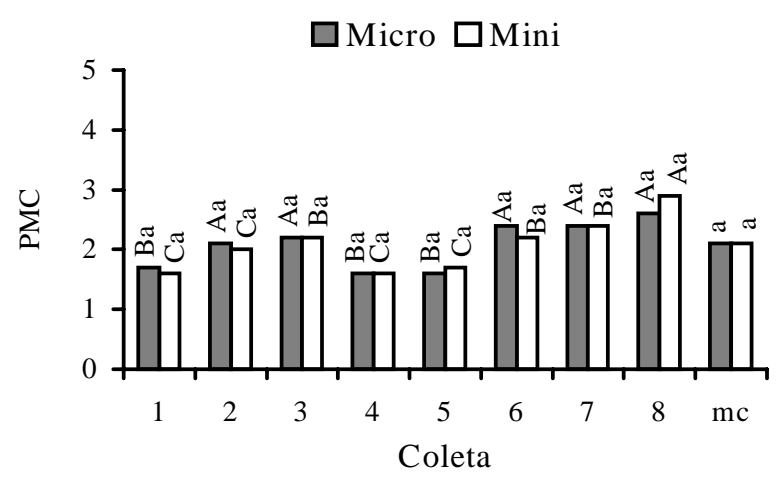

Clone CC12

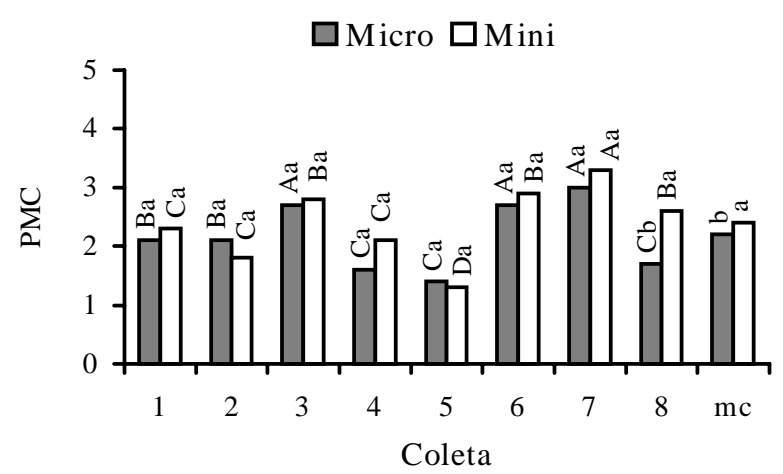

Média dos quatro clones

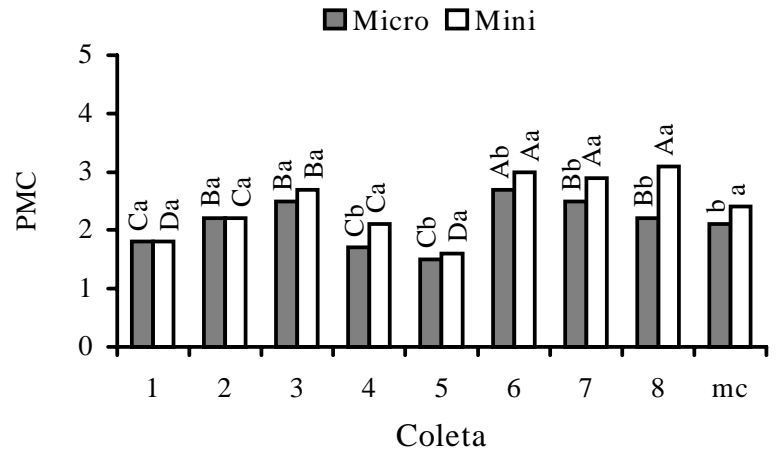

Figura 1 - Produção de microestacas (Micro) e miniestacas (Mini) por microcepa e minicepa por coleta (PMC) efetuada nos jardins microclonal e miniclonal dos quatro clones de Eucalyptus grandis e média das oito coletas (mc). As médias seguidas de uma mesma letra maiúscula dentro de uma mesma técnica e entre coletas e as seguidas de uma letra minúscula dentro da mesma coleta e entre técnicas, respectivamente, não diferem entre si pelo teste de Scott-Knott, a 5\% de probabilidade.

Figure 1 - Microcutting (Micro) and minicutting (Mini) productions per microstumps and ministumps per collection (PMC), in the microclonal and miniclonal gardens of the four Eucalyptus grandis clones, and average of the eight sucessive collections $(\mathrm{mc})$. Averages followed by the same capital letter in the same technique and among collections, and those followed by a lower case letter of the same collection and among techniques, respectively, do not differ by the Scott-Knott test, at $5 \%$ probability.

R. Árvore, Viçosa-MG, v.27, n.5, p.619-625, 2003 
A produção de microestacas e miniestacas variou entre clones e entre coletas, no entanto houve tendência cíclica em todos os clones. Nas coletas de número $4 \mathrm{e}$ 5 houve ligeiro decréscimo nos valores de produção, sendo tais valores, a partir da sexta coleta, maiores e mais estáveis até a realização da última coleta. $\mathrm{O}$ comportamento cíclico pode estar relacionado a uma exaustão temporária das microcepas e minicepas, ocasionando menores produções. A produção de microestacas, de acordo com Assis et al. (1992) e Xavier \& Comério (1996), e de miniestacas, segundo Wendling (1999), também apresenta oscilações com a mudança na temperatura.

Os clones $\mathrm{CC} 1$ e $\mathrm{CC} 12$ apresentaram os maiores valores médios de produção de miniestacas nas oito coletas. Já os clones CC8 e CC11 não exibiram diferenças na produção de microestacas e miniestacas nas oito coletas. Tem sido observado que mudas micropropagadas, após a decapitação do ápice, emitem poucas brotações, possivelmente em razão da persistência da dominância apical. Em coletas sucessivas, a depender do manejo dispensado às microcepas, pode-se observar aumento nas brotações emitidas e forte tendência à perda da dominância apical. Desta forma, clones mais juvenis teriam maior potencial de dominância apical, como nas microcepas, em que o manejo das brotações deve ser eficiente, de modo a garantir maior produção de microestacas.

No Quadro 2 estão os resultados referentes ao vigor das microcepas e minicepas, avaliados pelo número e tamanho das brotações emitidas.

A avaliação do vigor das microcepas e minicepas foi realizada até os 20 dias, em razão de várias brotações maiores que $4 \mathrm{~cm}$ de comprimento já estarem adequadas para a coleta de microestacas e miniestacas. Esse tempo requerido para formação e coleta das microestacas e

Quadro 2 - Número de brotações dos quatro clones de Eucalyptus grandis emitidas por microcepas e minicepas, distribuídas em três classes de tamanho (1, 2 e 3), avaliadas aos 3, 6, 9, 15 e 20 dias

Table 2 - Microstump and ministump sprouts of four Eucalyptus grandis clones, distributed in three size classes (1, 2 and 3), evaluated at 3, 6, 9, 15 and 20 days

\begin{tabular}{|c|c|c|c|c|c|c|c|c|c|}
\hline \multirow{4}{*}{ Clone } & \multirow{4}{*}{$\begin{array}{l}\text { Tempo } \\
\text { (dias) }\end{array}$} & \multicolumn{6}{|c|}{ Classe } & \multirow{3}{*}{\multicolumn{2}{|c|}{$\begin{array}{c}\text { Total } \\
>0,5 \mathrm{~cm}\end{array}$}} \\
\hline & & \multirow{2}{*}{\multicolumn{2}{|c|}{$\frac{1}{(0,5-2,0 \mathrm{~cm})}$}} & \multirow{2}{*}{\multicolumn{2}{|c|}{$\begin{array}{c}2 \\
(2,1-4,0 \mathrm{~cm})\end{array}$}} & \multirow{2}{*}{\multicolumn{2}{|c|}{$\frac{3}{>4,0 \mathrm{~cm}}$}} & & \\
\hline & & & & & & & & & \\
\hline & & Micro & Mini & Micro & Mini & Micro & Mini & Micro & Mini \\
\hline \multirow{5}{*}{ CC 1} & 3 & 3,5 & 1,8 & 0,0 & 0,0 & 0,0 & 0,0 & 3,5 & 1,8 \\
\hline & 6 & 4,1 & 4,6 & 0,1 & 0,3 & 0,0 & 0,0 & 4,3 & 4,9 \\
\hline & 9 & 5,8 & 7,6 & 1,3 & 1,6 & 0,0 & 0,3 & 7,0 & 9,5 \\
\hline & 15 & 3,1 & 4,0 & 2,6 & 2,0 & 4,4 & 5,8 & 10,1 & 11,8 \\
\hline & 20 & 3,3 & 5,1 & 1,1 & 0,8 & 6,0 & 7,1 & 10,4 & 13,0 \\
\hline \multirow{5}{*}{$\mathrm{CC} 8$} & 3 & 1,6 & 1,3 & 0,0 & 0,0 & 0,0 & 0,0 & 1,6 & 1,3 \\
\hline & 6 & 3,4 & 4,6 & 0,0 & 0,0 & 0,0 & 0,0 & 3,4 & 4,6 \\
\hline & 9 & 7,3 & 7,6 & 0,3 & 0,8 & 0,0 & 0,0 & 7,6 & 8,4 \\
\hline & 15 & 3,8 & 5,6 & 2,8 & 2,5 & 4,3 & 2,5 & 10,9 & 10,6 \\
\hline & 20 & 3,9 & 3,9 & 2,8 & 2,8 & 5,9 & 4,5 & 12,6 & 11,2 \\
\hline \multirow{5}{*}{ CC 11} & 3 & 4,6 & 2,3 & 0,0 & 0,0 & 0,0 & 0,0 & 4,6 & 2,3 \\
\hline & 6 & 7,0 & 6,3 & 1,0 & 0,0 & 0,0 & 0,0 & 8,0 & 6,3 \\
\hline & 9 & 5,0 & 4,4 & 3,5 & 3,1 & 0,5 & 0,3 & 9,0 & 7,8 \\
\hline & 15 & 3,0 & 3,0 & 3,1 & 1,5 & 7,8 & 6,5 & 13,9 & 11,0 \\
\hline & 20 & 3,0 & 3,1 & 2,5 & 1,0 & 8,4 & 7,4 & 13,9 & 11,5 \\
\hline \multirow{5}{*}{ CC 12} & 3 & 1,4 & 1,4 & 0,0 & 0,0 & 0,0 & 0,0 & 1,4 & 1,4 \\
\hline & 6 & 3,6 & 2,6 & 0,0 & 0,0 & 0,0 & 0,0 & 3,6 & 2,6 \\
\hline & 9 & 3,4 & 3,9 & 1,3 & 1,3 & 0,1 & 0,1 & 4,8 & 5,3 \\
\hline & 15 & 3,3 & 4,0 & 3,1 & 4,5 & 4,1 & 4,3 & 10,5 & 12,8 \\
\hline & 20 & 2,9 & $*$ & 2,6 & $*$ & 6,1 & $*$ & 11,6 & $*$ \\
\hline \multirow{5}{*}{ Médias } & 3 & 2,8 & 1,7 & 0,0 & 0,0 & 0,0 & 0,0 & 2,8 & 1,7 \\
\hline & 6 & 4,5 & 4,5 & 0,3 & 0,1 & 0,0 & 0,0 & 4,8 & 4,6 \\
\hline & 9 & 5,4 & 5,9 & 1,6 & 1,7 & 0,2 & 0,2 & 7,1 & 7,8 \\
\hline & 15 & 3,3 & 4,2 & 2,9 & 2,6 & 5,1 & 4,8 & 11,4 & 11,5 \\
\hline & 20 & 3,3 & 4,0 & 2,3 & 1,5 & 6,6 & 6,3 & 12,1 & 11,9 \\
\hline
\end{tabular}

* Dado não coletado. 
miniestacas foi superior a oito dias, pois as cepas utilizadas na presente avaliação tiveram todas as brotações retiradas, com o objetivo de verificar o potencial de emissão de novas brotações.

Na primeira medição, realizada aos três dias após a limpeza das cepas, o número médio de brotações emitidas por microcepa/minicepa, nos quatro clones, foi de 2,8 na microestaquia e de 1,7 na miniestaquia. Em todos os clones, essas brotações foram enquadradas na classe 1 (de 0,5 a 2,0 cm). Aos seis dias, os clones CC8 e CC12 apresentaram somente brotações de tamanhos inferiores a $2,0 \mathrm{~cm}$. O clone $\mathrm{CC} 1$ teve brotações que mediam entre 2,0 e 4,0 cm (classe 2), em ambas as técnicas, e o CC11, brotações acima de $2,0 \mathrm{~cm}$, encontradas apenas na microestaquia. Nos quatro clones, a média obtida foi de 4,8 e 4,6 brotações/cepa, na microestaquia e miniestaquia, respectivamente.

Na medição realizada aos nove dias, a média geral na miniestaquia foi de 7,8 brotações/cepa e na microestaquia, de 7,1. Todos os clones apresentaram brotações dentro das classes 1 e 2. Os clones CC11 e CC12 exibiram também brotações que se enquadravam na classe 3 , nas duas técnicas. No entanto, o maior número de brotações foi obtido dentro da classe 1. Já aos 15 dias, observou-se certo equilíbrio do número de brotações nas três classes, com a ressalva de que nos clones CC1 e CC11 a classe 3 passou a apresentar os maiores valores.

Ao final de 20 dias, observou-se que as brotações da classe 3 apresentaram, em termos gerais, os maiores valores, seguida daquelas da classe 1 . A classe 2 foi a que exibiu o menor número de brotações, possivelmente devido à forte dominância apical exibida pelas brotações mais desenvolvidas, que inibem o desenvolvimento e a progressão entre as brotações menores que $2 \mathrm{~cm}$.

De modo geral, o número de brotações emitidas pelas microcepas e minicepas, em relação aos diferentes tempos de mensuração e clones, não diferiu entre as duas técnicas, o que indica que as microcepas e minicepas apresentam potencial semelhante para emissão de brotações.

Após a medição aos 20 dias, todas as brotações foram coletadas para determinação do peso de matéria seca. Na Figura 2, observa-se que apenas o clone CC1 apresentou diferença estatística entre as técnicas de produção de mudas. Entretanto, na média dos clones, os valores obtidos nas microestacas e miniestacas foram semelhantes, o que concorda com os resultados obtidos anteriormente para produção de microestacas e miniestacas.

É oportuno salientar que, embora os resultados de produção, vigor e sobrevivência das minicepas e microcepas obtidos no trabalho sejam similares, eles não indicam, necessariamente, que o enraizamento das miniestacas e microestacas responda da mesma forma. Resultados obtidos por Titon (2001) e Xavier et al. (2001), por exemplo, têm sinalizado desempenho superior da microestaquia, em relação à miniestaquia.

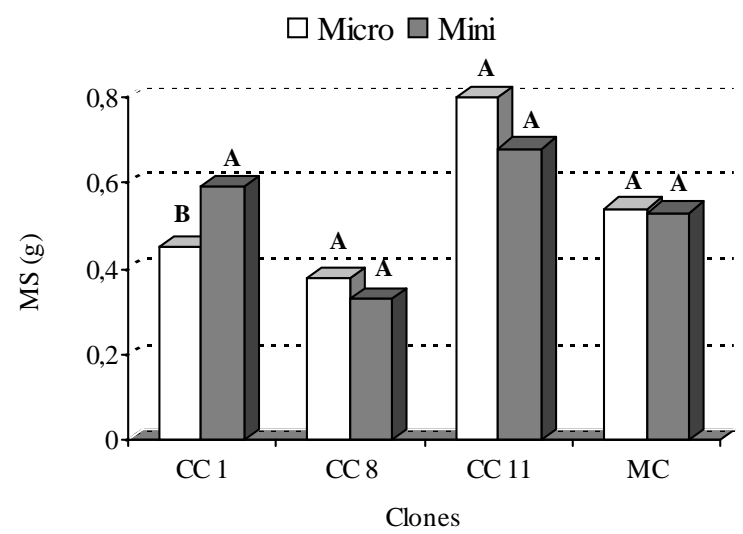

Figura 2 - Peso de matéria seca (MS) das brotações de três clones de Eucalyptus grandis produzidas pelas microcepas (Micro) e minicepas (Mini) coletadas no final de 20 dias e média dos clones (MC). Médias seguidas de uma mesma letra não diferem entre si pelo teste de Tukey, a $5 \%$ de probabilidade.

Figure 2 - Dry matter weight (MS) of sprouts of three Eucalyptus grandis clones, produced by the microstumps (Micro) and ministumps (Mini) collected after 20 days and clone average (MC). Averages followed by the same letter do not differ by the Tukey test, at 5\% probability.

\section{CONCLUSÕES}

Em termos gerais, quanto a produção, vigor e sobrevivência, as microcepas e minicepas apresentaram resultados semelhantes. Esses resultados evidenciam que, para os clones em estudo e dentro das condições de manejo adotadas, as técnicas de microestaquia e miniestaquia podem ser consideradas eficientes na produção de propágulos, visando a propagação clonal.

Quanto ao rejuvenescimento in vitro, pode-se inferir que este não promoveu diferenças significativas na sobrevivência, na produção e no vigor das microcepas em relação às minicepas. Em parte, esses resultados são 
decorrentes do material genético (clones) utilizado, bem como do grau de juvenilidade das microcepas e minicepas e das condições ambientais durante a propagação.

\section{AGRADECIMENTO}

À Empresa Celulose Nipo-Brasileira S.A. (CENIBRA), pela oportunidade da realização do trabalho nas dependências do viveiro florestal e pela disponibilização do material genético (clones); e à CAPES (Coordenadoria de Aperfeiçoamento de Pessoal de Ensino Superior), pelo suporte financeiro.

\section{REFERÊNCIAS BIBLIOGRÁFICAS}

ASSIS, T. F. Propagação vegetativa de Eucalyptus por microestaquia. In: REUNIÃO TÉCNICA DE PROPAGAÇÃO VEGETATIVA, 11., REUNIÃO DE SILVICULTURA CLONAL, 1., 1996, Piracicaba. Anais... Piracicaba: ESALQ/USP, 1996. p. 1-9.

ASSIS, T. F. Propagação vegetativa de Eucalyptus por microestaquia. In: IUFRO CONFERENCE ON SILVICULTURE AND IMPROVEMENT OF EUCALYPTS, 1997, Salvador. Proceedings... Colombo: EMBRAPA, 1997. v. 1. p. 300-304.

ASSIS, T. F.; ROSA, O. P.; GONÇALVES, S. I. Propagação por microestaquia. In: CONGRESSO FLORESTAL ESTADUAL, 7., 1992, Nova Prata. Anais... Santa Maria: Universidade Federal de Santa Maria, 1992. p. 824-836.

BONGA, J. M. Vegetative propagation in relation to juvenility, maturity and rejuvenation. In: BONGA, J. M.; DURZAN, D. J. (Eds.). Tissue culture in forestry. Boston: Martinus Hijhoff/Dr W., Junk Publishers, 1982. p.387-412.

CHALFUN, N. N. J. Fatores bioquímicos e fisiológicos no enraizamento de estacas de Hibiscus rosa-sinensis $\mathrm{L}$. 1989. 85 f. Tese (Doutorado em Fitotecnia) Universidade Federal de Viçosa, Viçosa, 1989.

HACKETT, W. P. Juvenility and maturity. In: BONGA, J. M.; DURZAN, D. J. (Eds.). Cell and tissue culture in forestry. Dordrecht: Kluwer Academic Publishers, 1987. v. 1 . p. $216-231$.
HIGASHI, E. N.; SILVEIRA, R. L. V. A.; GONÇALVES, A. N. Propagação vegetativa de Eucalytpus: princípios básicos e a sua evolução no Brasil. Piracicaba: ESALQ/ USP, 2000. 11 p. (Circular Técnica IPEF, 192).

INSTITUTO DE PESQUISAS E ESTUDOS FLORESTAIS - IPEF. Sistemas alternativos de microjardim clonal via solução nutritiva. Boletim Informativo IPEF, v. 2, n. 15, p. 1-2, 1996.

SILVA, L. F. Propagação vegetativa do eucalipto: experiência da International Paper do Brasil. IPEF Notícias, v. 25, n. 156, p. 4-5, 2001.

TITON, M. Propagação clonal de Eucalyptus grandis por miniestaquia e microestaquia. 2001. 65 f. Dissertação (Mestrado em Ciência Florestal) - Universidade Federal de Viçosa, Viçosa, 2001.

WENDLING, I. Propagação clonal de híbridos de Eucalyptus spp. por miniestaquia. 1999. $70 \mathrm{f}$.

Dissertação (Mestrado em Ciência Florestal) - Universidade Federal de Viçosa, Viçosa, 1999.

WENDLING, I. et al. Propagação clonal de híbridos de Eucalyptus spp. por miniestaquia. Revista Árvore, v. 24, n. 2, p. 181-186, 2000.

XAVIER, A.; COMÉRIO, J. Microestaquia: uma maximização da micropropagação de Eucalyptus. Revista Árvore, v. 20, n. 1, p. 9-16, 1996.

XAVIER, A.; WENDLING, I. Miniestaquia na clonagem de Eucalyptus. Viçosa, MG: SIF, 1998. 10 p. (Informativo Técnico SIF, 11).

XAVIER, A. et al. Desempenho do enraizamento de microestacas e miniestacas de clones híbridos de Eucalyptus grandis. Revista Árvore, v. 25, n. 4, p. 403-411, 2001.

ZOBEL, B. J. Clonal forestry in the eucalypts. In: AHUJA, M. R.; LIBBY, W. J. (Eds.). Clonal forestry: conservation and application. Budapest: Springer-Verlag, 1993. p. 139148 . 